\title{
THE EFFECTS OF INNOVATION ON VERTICAL STRUCTURE: PERSPECTIVES ON TRANSACTION COSTS AND COMPETENCES
}

\author{
CLAUDIO WOLTER \\ Carnegie Mellon University \\ FRANCISCO M. VELOSO \\ Carnegie Mellon University and Universidade Católica Portuguesa

\begin{abstract}
We analyze how transaction cost economics and competence arguments determine vertical organization boundaries when firms react to innovation. Existing perspectives and empirical evidence have been ambiguous because of conflicting tensions between the two frameworks and simplistic views of innovation. Using Henderson and Clark's (1990) innovation categories and a careful review of both theories, we show that it is possible to reach $\alpha$ consistent set of predictions on vertical integration and to reconcile apparently conflicting empirical results.
\end{abstract}

Specialization of productive activities and, more generally, the theory of the firm have been of interest to economists ever since Smith (1776) illustrated how the division of labor that comes about with growth in the extent of the market increases manufacturing productivity. Since then, many scholars in the fields of transaction cost economics (TCE) and resource-based theory have made theoretical contributions to our understanding of how transaction costs and firm capabilities jointly shape firms' vertical boundaries in relatively static business environments. Moreover, the independent effects of transaction costs and capability heterogeneity on firms' vertical integration decisions are strongly supported by empirical evidence (Argyres, 1996; Jacobides \& Hitt, 2005; Leiblein \& Miller, 2003).

Unfortunately, our confidence in these results cannot be extended to the determination of firm boundaries in more dynamic environments, despite the fact that the importance of doing so has long been identified (Globerman, 1980). Most studies of vertical structure incorporating TCE

We thank Sebastian Fixson, Claudia Gonzalez-Brambila, Glenn Hoetker, Michael Jacobides, Lamar Pierce, Filipe Santos, Brian Silverman, Peter Thompson, Antonino Vaccaro, and participants at the INFORMS 2005 annual meeting for helpful comments on earlier drafts of this manuscript. Financial support from the International Motor Vehicle Program is gratefully acknowledged. and firm competences ${ }^{1}$ have neglected innovation, a phenomenon that is at the core of the Schumpeterian view of economic change and life-cycle theories (Afuah, 2001; Cacciatori \& Jacobides, 2005; Teece, 1996). Leiblein and Miller, for example, note that existing studies have failed "to account for the value associated with the ability to react flexibly to an uncertain future" (2003: 842).

Technological change reasonably complicates the task of identifying transaction costs, relevant competences, and how the interplay between them shapes firm boundaries. Williomson (1985), for instance, admitted that, contrary to what happens in the static case, transaction costs emerging uniquely from asset specificity would be less than persuasive in explaining vertical structure in an innovative environment. Incorporating concepts from a competence perspective, such as learning or dynamic capabilities, into a more general theory of innovation and vertical structure creates even more challenges. Moreover, empirically dealing with technological change means obtaining longitudinal data on the already hard to obtain constructs of transactions and capabilities.

In spite of these difficulties, a better understanding of this relationship between techno-

\footnotetext{
${ }^{1}$ In this paper we use "capabilities" and "competences" interchangeably, as has been usual in the literature (cf. Afuah, 2001; Henderson \& Clark, 1990; Teece, Pisano, \& Shuen, 1997).
}

Copyright of the Academy of Management, all rights reserved. Contents may not be copied, emailed, posted to a listserv, or otherwise transmitted without the copyright holder's express written permission. Users may print, download, or email articles for individual use only. 
logical change and firm boundaries is absolutely necessary. Not only may firms need to alter their boundaries as a response to exogenous innovations, but their vertical structures and associated links to external suppliers may also have a direct influence on their innovative activities (Teece, 1996). Understanding these issues is also critical because there is apparently conflicting empirical evidence regarding the effects of technological uncertainty on firms' integration decisions (Dyer, 1996) - that is, whether uncertainty leads to integration or disintegration at the firm level (Hoetker, 2005; Schilling \& Steensma, 2002; Walker \& Weber, 1987).

Because of substantial differences across industries (e.g., services versus manufacturing), as well as in possible ways of characterizing innovations, we recognize, as do Langlois and Robertson (1989), that a general theory of vertical integration in an environment of technological change might presently still be out of reach. Yet we hope in this paper to shed some light on these issues in at least one particular setting; we analyze how transaction cost and competence arguments interplay and relate to vertical integration decisions in the context of various product innovations in manufacturing firms.

Hence, following recent studies combining TCE and the competence perspective to understand firm boundaries (Jacobides \& Hitt, 2005; Jacobides \& Winter, 2005; Sampson, 2004; Silverman, 1999), our main objectives in this paper are twofold: first, to extend the positive theories of firm boundaries by trying to understand how market structure evolves as a result of firms' altering their degree of vertical integration in response to exogenous technological shocks, and, second, to explore firm-level competences and TCE as the underpinnings of a normative theory of vertical integration and technological change, with the aim of informing decision makers about the strategic management of value chains, with innovation and competitive advantage as targets.

Treating innovation initially as exogenous to the firms and later as endogenous simplifies the exposition of arguments and allows us to explore possible differences in the efficiency of governance structures between leaders and followers. We also believe it is possible to reconcile extant theory with the previously noted conflicting empirical evidence about the effects of technological uncertainty on the direction of firm-level integration. As such, a final objective of this paper is to suggest directions for future empirical work through the presentation of testable propositions.

To reach these goals, a careful definition of the analysis context is critical. Part of the difficulty in understanding the effects of transaction costs and competences on vertical boundaries in dynamic settings stems from a lack of clarity in characterizing the industry and, especially, the innovation that is being analyzed. Hence, we focus on multitechnology, multicomponent industries, such as the computer or automotive industry, and develop our main propositions from the viewpoint of a systems integrator (or assembler) ${ }^{2}$ responding to a technological shock. We characterize each type of innovation using Henderson and Clark's (1990) typology: incremental (or component), modular, architectural, and radical. We then look at how transaction cost and competence arguments simultaneously influence make-or-buy decisions in each case.

Henderson and Clark's (1990) conceptualization has the advantage of combining Teece's (1996) autonomous versus systemic dichotomy with Tushman and Anderson's (1986) competence-enhancing versus competence-destroying dichotomy. ${ }^{3}$ In fact, considering the various dimensions associated with an innovation, it is highly unlikely that any one type of governance mode, be it internal organization, reliance on markets, or additional hybrid forms (e.g., joint ventures), would be able to successfully deal

\footnotetext{
${ }^{2}$ We use "systems integrators" and "assemblers" interchangeably throughout the text. They denote a firm that manufactures a final product requiring upstream parts produced either inhouse or bought in an intermediate market. Assemblers can be more or less integrated depending on how much of the final product is produced internally.

${ }^{3}$ An autonomous innovation can be introduced without modifying other components in the system. In contrast, a systemic one requires significant modifications in other parts of the product. Similarly, a competence-enhancing innovation is an improvement building on existing know-how, whereas a competence-destroying one is "so fundamentally different from previously dominant technologies that the skills and knowledge base required to operate the core technology shift" (Tushman \& Anderson, 1986: 442). Hence, an incremental innovation is characterized as an autonomous, competence-enhancing innovation; a modular one as an autonomous, competence-destroying innovation; an architectural one as a systemic, competence-enhancing innovation; and a radical one as a systemic, competence-destroying innovation.
} 
with all forms of innovation (Conner \& Prahalad, 1996). We also believe that while innovation typologies have provided interesting ex post rationalizations and explanations for a number of economic phenomena, their true value as a tool in the social sciences will only be proved if they can lend themselves to the construction of ex ante testable empirical hypotheses.

In the following section we present the transaction cost reasoning for vertical integration when innovation is present. This is followed by an analogous presentation of arguments from the competence perspective. Next, we develop our main propositions by discussing both perspectives as applied to Henderson and Clark's (1990) innovation typology and from the viewpoint of a systems integrator. This is further extended to include the endogenous development of innovations. In the final section we discuss the limitations of this study and point to directions where future research might prove more fruitful.

\section{TECHNOLOGICAL UNCERTAINTY AND VERTICAL STRUCTURE}

\section{Transaction Cost Perspective}

Building on Smith's (1776) work, Stigler (1951) realized that although the intrafirm division of labor is indeed a matter of productivity (Langlois, 1988), activities characterized by production functions displaying increasing returns to scale could be organized more efficiently in new independent firms (suppliers). Therefore, the extent of the market would also determine the degree of integration in an industry.

The problem with the Smith-Stigler focus on production costs is its incompleteness. Without further assumptions about the costs of internal organization (Masten, Meehan, \& Snyder, 1989) and the costs of using markets for transacting, arguments about the division of labor do not directly translate into predictions about vertical integration (Langlois, 1992). These governance costs were first identified by Coase (1937) as important determinants of firm boundaries. Thirty years later, TCE developed and operationalized Coases's concepts and thus emerged as a strong explainer of these boundaries (Williamson, 1971; Williamson, 1975).

TCE recognizes the incompleteness of all contracts, since firms can neither have perfect in- formation nor possibly foresee all future contingencies. It also assumes that economic actors behave not only in a bounded rational way but also in an opportunistic way. Because contract renegotiations are costly, bounded rationality, opportunism, and relationship-specific investments expose one of the transacting parties to the hazards of ex post holdups (Williamson, 1985). In addition, ex ante uncertainty creates strategic misrepresentation risks, such as moral hazard (Williamson, 1971). Either situation may lead to the nonrealization of or underinvestment in otherwise lucrative relationships. The major sources of transaction costs identified in the literature (Williamson, 1983) are uncertainty, the frequency of contract updates, and asset specificity (physical, human, site, and dedicated assets). The higher the uncertainty, frequency, or specificity governing contracts in a relationship, the higher transaction costs will be. Therefore, firms will organize their boundaries to minimize these costs.

Let us start by examining in some detail which factors raise transaction costs in an innovative environment. As previously noted, asset specificity is one of these if the development of the innovation requires upstream or downstream firm-specific investments by one or more transacting partners. The completion of these investments, the so-called fundamental transformation (Williamson, 1985), results in a small numbers bargaining situation that exposes at least one party to the hazards of opportunistic holdups or strategic misrepresentation. Vertical integration prevents unnecessary haggling and uses fiat to harmonize interests, risk perception, expectations, and resource allocation (Williamson, 1971). The frequency with which a transaction recurs is another incentive for integration, since it directly increases haggling costs.

Uncertainty in a general sense increases transaction costs because it causes contract updates and renegotiations. Even in the absence of opportunism or first mover advantages resulting from the ex post small numbers bargaining, renegotiations do involve reasonable costs (Conner \& Prahalad, 1996; Mayer \& Argyres, 2004; Williamson, 1971). Uncertainty also complicates the process of hostage exchange (de Figueiredo \& Teece, 1996). Thus, in principle, higher uncertainty will lead to higher degrees of vertical integration in an industry. Internal organization mitigates these problems by allowing firms to 
better cope with uncertainty through the use of adaptive sequential decisions (Langlois, 1988; Masten, 1984; Williamson, 1975).

Nevertheless, uncertainty is not a unidimensional construct. Although it is decomposed in different ways in the literature, one common way is to consider two key dimensions: (1) technological or product uncertainty and (2) demand, also known as market or commercial uncertainty. To clearly separate both dimensions, we consider demand uncertainty as that exogenous to the innovation process - that is, uncertainty in market demand for a product due to factors other than the technology itself. Macroeconomic effects, regulatory uncertainty, and changes in consumer preferences fall under this category. By the same token, technological uncertainty includes a market demand component caused not only by (functionality- or quality-adjusted) product price (or production costs) achieved with the given technology but also by diffusion factors, such as network externalities and bandwagon effects. In this paper we are primarily interested in the effects of technological uncertainty.

Although empirical studies have systematically supported the propositions that the frequency of transactions, demand uncertainty, and especially asset specificity are positively associated with vertical integration, results are mixed, to say the least, when testing the influence of technological uncertainty. Walker and Weber (1987), for instance, showed that high technological uncertainty with thick upstream markets in the automotive industry led to the procurement of components in the market (contrary to TCE predictions), whereas there was no statistically significant influence with thin upstream markets. In contrast, Hoetker (2005) demonstrated that high technological uncertainty in the development of innovative notebook displays drove computer makers to integrate backwards.

Other studies have found weak or nonexistent links between technological uncertainty and vertical integration. In a study of markets for technology, Schilling and Steensma (2002), for example, divided technological uncertainty into two constructs: technological dynamism and commercial uncertainty (purely due to the technology itself). They showed that whereas the former had no effect on the choice of governance mode, the latter led to licensing decisions (disintegration), rather than acquisitions (integra- tion). Also, Poppo and Zenger (1998) found no relationship between technological uncertainty and the outsourcing of information services by major American companies.

One possibility for this lack of empirical agreement regarding technological uncertainty is that the competence perspective may play an important part in an innovative setting (different from that in a purely static one), diluting the influence of TCE as a driver of integration. This is where we turn to next.

\section{Competence Perspective}

From its original exclusive focus on transactions as the unit of analysis, TCE has since been broadened to include the minimization of both transaction and production costs. Although some of the initial efforts to combine transaction and production costs emerged within the context of corporate diversification decisions (Teece, 1980, 1982), the literature on vertical integration soon followed.

Riordan and Williamson (1985) pioneered the inclusion of production costs into the minimization effort. They considered production cost differences a result of scale economies. But cost differences due to scale can also be seen as the result of transaction costs, since firms' internal suppliers might find it horder than independent ones to sell parts to competitors because of the perceived hazards (Argyres, 1996). Consequently, scholars began concentrating their efforts on the incorporation of the competence (or capabilities) perspective of the firm, which had more recently emerged in the strategic management literature to explain firm heterogeneity in production costs, conduct, and performance. This perspective also illuminates the concept of the market, which, rather than an abstract institution, is in reality composed of other firms with their own idiosyncratic production capabilities and costs. The boundaries between a focal firm and the market is then that between the firm and all of these external enterprises (Jacobides \& Winter, 2005; Madhok, 2002).

Competences, a term we use here in a way similar to Foss (1993) - that is, in a general sense to refer to the resource-based view (RBV; Barney, 1986; Peteraf, 1993; Wernerfelt, 1984), evolutionary theory (Nelson \& Winter, 1982), and the knowledge-based view of the firm (KBV; Kogut \& Zander, 1992)_are much more than production 
costs or production functions. They involve lowand higher-order routines, knowledge, skills, and learning (Langlois, 1988) and are the result of technical and organizational components endogenously influencing each other (Madhok, 2002). Absent capabilities, firms facing the same type of transactions and having the same scale would end up with the same governance structure (Leiblein \& Miller, 2003). Therefore, factoring capability heterogeneity into make-or-buy decisions became the next logical step.

Heterogeneity in firm capabilities has a direct impact on make-or-buy decisions. Firms tend to specialize in activities where they have some comparative advantage (Jacobides \& Winter, 2005; Kogut \& Zander, 1992; Richardson, 1972; Teece, 1996). The incorporation of this competence perspective into the original TCE framework led Williamson, for instance, to suggest that "TCE informs the generic decision to makeor-buy while competence hinges in particulars" (1999: 1097). Langlois (1992) went further, arguing that although both transaction costs and capabilities matter, the former are short-run phenomena that tend to lose importance when learning takes place through transacting, a view similarly expressed by Foss (1993).

As previously remarked, empirical studies have confirmed the independent effects of capabilities and transaction costs on the choice of governance mode in many different industries. Studying the production of wires, cables, and connectors, Argyres (1996) demonstrated that, in some cases, asset specificity (human and site) is the dominant explanation of make-or-buy decisions, whereas in other situations production costs unrelated to scale are determinant. Independent effects of capabilities are also found, for example, in the semiconductor industry (Leiblein \& Miller, 2003), in the production of notebook displays (Hoetker, 2005), and in the mortgage banking industry (Jacobides \& Hitt, 2005). A formal analytical model proposed by Jacobides (2008) suggests that capabilities could be the main drivers of make-or-buy decisions in certain manufacturing sectors, whereas empirical results from the information technology sector show that transactional issues dominate in this context (Mayer \& Nickerson, 2005).

When dealing with innovations, however, it becomes necessary to move beyond a static representation of capabilities to a broader competence perspective of the firm, including resources, knowledge, skills, routines, and learning, in order to address the effects of technological uncertainty on firms' boundaries. According to Langlois, this competence perspective should include a "real-time account of production costs where knowledge and organization have as important a role as technology" (1992: 107-108).

Even though Williamson (1971) had already recognized the coordination potential of the firm, the KBV explicitly argues that the raison d'être of firms is to create and transfer information and know-how efficiently (Kogut \& Zander, 1992). According to the KBV, firms in an innovative environment characterized by technological uncertainty internalize activities not because of disadvantages (transaction costs) associated with market exchanges but, rather, because of the benefits of coordinating ex ante, and within the same organization, complementary (and similar) activities (Conner \& Prahalad, 1996; Kogut \& Zander, 1992; Richardson, 1972). ${ }^{4}$

These advantages arise because organizations develop routines and language tools through training (Armour \& Teece, 1980; Williamson, 1971) and repeated interpersonal relations ${ }^{5}$ (Hoetker, 2005; Kogut \& Zander, 1992) so as to economize on communication costs. These routines become highly efficient in transferring knowledge or in tackling tasks that require quick adaptation (Argyres, 1996; Langlois, 1988).

Internal organization also benefits from the power of managerial fiat (Williamson, 1971) to solve problems of information asymmetry, which can arise even without opportunism. Technological uncertainty might result in honest parties' unintentionally keeping some knowledge private, leading to disagreements about the optimal allocation of tasks and re-

\footnotetext{
${ }^{4}$ These are net benefits from which organizational bureaucratic costs (Coase, 1937) have been discounted. Although Argyres (1996) has argued that firms do not necessarily have bureaucratic disadvantages when compared to markets, many scholars are of the opposite opinion (Balakrishnan \& Wernerfelt, 1986; Masten, 1984; Nickerson \& Zenger, 2004; Williamson, 1975).

${ }^{5}$ Williamson (1999) disagrees with this argument since these advantages can also be developed during long-term interfirm transactions. Helper, MacDuffie, and Sabel (2000) call this process "learning by monitoring." However, empirical evidence suggests that firms indeed have advantages in the development and efficiency of these relations (Masten et al., 1989).
} 
sources (Conner \& Prahalad, 1996). This issue is related to the presence of high degrees of tacit knowledge. ${ }^{6}$ Because tacit knowledge can more easily be appropriated by and transferred within a single firm, vertical integration would once again be the preferred outcome to prevent knowledge leakage (Argyres, 1996; Christensen, Verlinden, \& Westerman, 2002; Teece, 1982). As a matter of fact, integration has been seen more generally as a strategic move to enhance the appropriability of knowledge in regimes of weak intellectual property (Teece, 1986).

Christensen et al. (2002) seem to agree with the KBV perspective. They argue that when customers are underserved by a technology whose future path is still uncertain, firms are constantly trying to push the possibility frontier of their products with interdependent designs. This interdependency, meaning that interfaces within the product architecture are not well specified so that changes in design specifications of one component can easily affect additional ones, involves a lot of tacit knowledge and requires unstructured technical dialogue (Monteverde, 1995), which is best accomplished within the boundaries of a single firm.

Up to this point, this competence perspective of the firm has basically led to the same prediction as that from TCE regarding technological uncertainty and vertical structure. That is, the more uncertainty there is, the more vertical integration one should expect to observe in an industry. However, there are alternative reasonings that point in the opposite direction and that, as we suggested before, could be confounding empirical results on the effects of technical uncertainty on vertical integration.

In a regime of rapid technological change where the innovation trajectory is uncertain, the unique intraorganizational language and routines that are so efficient in creating and transferring knowledge might become the wrong ones. Integration will then promote an inflexibility or rigidity that might hinder the firm's effort to successfully acquire new knowledge and to innovate (Afuah, 2001; Langlois, 1992; Leonard-Barton, 1992; Poppo \& Zenger, 1998). Furthermore, investments not only in new knowl-

\footnotetext{
${ }^{6}$ Note that both information asymmetry and tacit knowledge can increase transaction costs because of contractual hazards, in addition to benefiting internal organization (Schilling \& Steensma, 2002).
}

edge and routines but also in semi-specialized capital goods or other tangible resources face $\alpha$ high risk of quick technological obsolescence (Balakrishnon \& Wernerfelt, 1986; Schilling \& Steensma, 2002).

Integrated firms may also miss out on innovations simply by being tied to a single internal supplier (Langlois \& Robertson, 1989). Independent suppliers have greater incentives than internal ones to expand their knowledge and skill bases, keeping abreast of new technological developments in order to continuously expand their customer base (Nooteboom, 1999; Poppo \& Zenger, 1998). Consequently, intermediate markets may offer a pluralism of technological alternatives in the form of capabilities and resources that any firm can access at any time. And this heterogeneity of available technological trajectories may confer evolutionary advantages to disintegrated firms, if these can indeed benefit from accessing distant and dissimilar knowledge and resources, as predicted by the Schumpeterian view of innovation as recombinations (Langlois, 1992).

Hence, according to these latter arguments, vertical disintegration should be the logical outcome of technological uncertainty. Although some scholars such as Langlois (1992) believe that the evolutionary benefits provided by the market-and that function analogously to Marshallian external economies (Nooteboom, 1999) - do indeed outweigh the benefits of vertical integration previously discussed (both in TCE and competence terms), this is still an open empirical question.

We are not arguing here that TCE is wrong when claiming that uncertainty (technological uncertainty included) increases transaction costs across the board in an industry, thus promoting higher degrees of vertical integration. Much to the contrary, we agree that, even holding asset specificity constant, higher uncertainty will lead bounded rational actors to spend more resources on contractual contingency clauses. And in the event that these break down, time-consuming renegotiations where the possibility of opportunistic behavior is present will be necessary between parties. These costs could then be avoided through common ownership, where disputes can be resolved by fiat. An integrated vertical structure would, in addition, benefit the transfer and coordination of knowledge between units of an organization. 
Nonetheless, we also argue that technological uncertainty by itself, and as frequently used in the empirical literature, is an insufficient construct to characterize technological change and to predict the direction of vertical integration in an industry. Technological uncertainty might or might not lead to more integration (as illustrated by the empirical results cited earlier), depending on whether firms' capabilities are overturned and how strong the incentives are to access new capabilities in the market. It thus becomes necessary to understand innovations in a more fine-grained manner.

In summary, it is possible to see that although TCE always predicts an increase in integration incentives with technological change and uncertainty, the competence perspective brings in an intrinsic tension to the way firms should respond. This tension arises from the conflicting needs of transferring and protecting knowledge and capabilities within the firm and of accessing new or alternative competences and knowledge bases in the market, thus mitigating the risk of technological obsolescence. Therefore, in some cases it is possible that the competence view will reinforce TCE's call for integration, whereas in other cases it will be pulling in the opposite direction. To understand these incentives at the firm level, we analyze the above arguments in view of the four kinds of (exogenous) innovations described by Henderson and Clark (1990). Not only are responses to distinct innovations important, since they affect firms' structure, conduct, and performance, but focusing on particulars may help explain the conflicting empirical evidence regarding the effects of technological uncertainty on vertical integration.

\section{INNOVATION AND VERTICAL STRUCTURE}

\section{Responding to Exogenous Shocks}

First, we are interested in how the degree of integration in an industry ${ }^{7}$ will change owing to one of the four exogenous technological shocks in the typology. In other words, our interest here is in the response of systems integrators to innovations arising outside their boundaries-that is, innovations emerging from sources external to the industry, from indepen-

\footnotetext{
${ }^{7}$ The long-term, path-dependent process by which the industry reached its present structure is irrelevant to us.
}

dent upstream suppliers, or within a competing, more integrated assembler. ${ }^{8} \mathrm{We}$ assume that regardless of the innovation type and where it initially materialized, alternative technological solutions always emerge in the marketplace from independent suppliers. And provided their capabilities have not been overturned, imitation by integrated assemblers is also possible. That is, replication occurs because the appropriability regime is weak. ${ }^{9}$

The easiest case to analyze is that of incremental innovations in the value chain. This is a product innovation where the core concepts of components are reinforced and there are no changes in the linkages or interfaces between these components (Henderson \& Clark, 1990). Therefore, upstream capabilities in the industry are not overturned by the innovation, wherever this is developed. Moreover, any investments in additional capabilities to replicate the innovation have a very low risk of obsolescence, since there are no major shifts in the innovation trajectory. As a consequence, integrated assemblers have no a priori incentives to disintegrate and use the market, since they can use their internal suppliers to play catch-up.

For a less integrated assembler, internalization incentives arising from incremental innovations are not significant either. First of all, the nature of the innovation implies that there is not much need for adaptation and knowledge transfer between the assembler and its supplier. In addition, relatively low technological uncertainty translates into low transaction costs. ${ }^{10}$

\footnotetext{
${ }^{8}$ An implicit assumption in this paper is that integration or disintegration occurs as a result of actions taken by assemblers and that upstream suppliers do not have the necessary systems integration capabilities to forward integrate.

${ }^{9}$ Teece (1996) considers a weak appropriability regime the common situation in most industries.

${ }^{10}$ We are naturally holding constant all other factors that could also raise transaction costs, such as frequency of transactions and demand uncertainty. The same is true of asset specificity. We believe that there is not enough evidence to pose a relationship between the nature of innovations and the asset specificity of new investments. Hoetker, for example, writes that "interviews indicate that beyond the specificity present in any innovative [notebook] display, increasing uncertainty impedes communication and the ability to contract for technical contingencies much more than it increases asset specificity" (2005: 78). Moreover, if asset specificity increases with technological uncertainty, our analysis is still valid. The same is true of monitoring costs (Alchian \& Demsetz, 1972).
} 
And long-term relationships with independent suppliers help to decrease even more these transaction and coordination costs through reputational effects, learning within the relationship (Mayer \& Argyres, 2004), and the establishment of a common interorganizational language (Langlois, 1992).

Hence, vertical scope in an industry suffering an incremental technological shock is determined primarily by capability differentials. And since these capabilities are not overturned by the innovation, industry structure should not change. In a sense, this is the closest to a static analysis. Integrated assemblers will tend to remain integrated and use their internal suppliers (a sunk investment) to replicate the innovation, whereas disintegrated ones will still turn to the market where they can access a number of tech- nological alternatives without the costs of integrating.

Figure 1 depicts these arguments. The right side represents integration incentives. Transaction cost arguments, represented within the dotted box on the right-hand side, call for greater integration the more uncertain an innovation is. These arguments are reinforced by the knowledge-based view of the firm, part of the competence perspective. We follow Globerman (1980) in considering that both transaction costs and coordination needs concurrently and monotonically increase as we move toward more "complex" innovations-that is, from incremental to modular, architectural, and then radical. In other words, moving from one extreme to the other simultaneously increases the need of suppliers and buyers to exchange more information

FIGURE 1

Framework for the Evolution of Industry's Vertical Scope After a Technological Shock

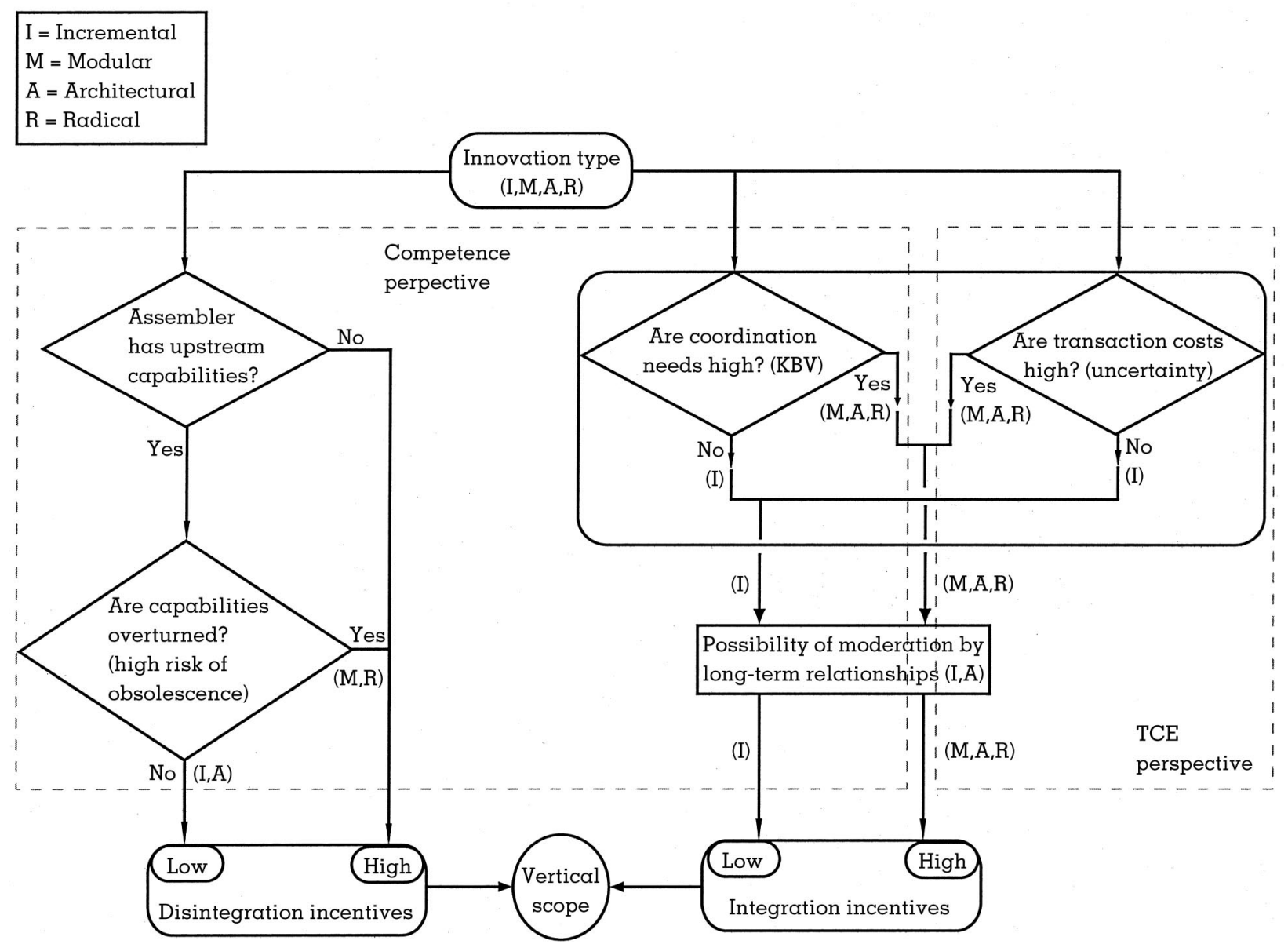


and increases the hazards associated with possible holdups and contract renegotiations that increase transaction costs. ${ }^{11}$ Since both effects lead to equivalent integration incentives, they mirror each other and are represented inside the same solid box in the upper right-hand side of Figure 1.

In contrast, the left side of Figure 1 illustrates what happens with upstream capabilities in the industry after an innovation is introduced, thus determining incentives to access the market, or disintegrate. As explained in the previous section, this is also a dimension of the competence perspective in an innovative setting, although distinct from the KBV. The dotted box on the left represents the two opposing aspects of this perspective.

When reading the figure for the case of incremental innovation, starting on the right side of the diagram, one can see that transaction costs and coordination needs are relatively low. Moreover, they can be reduced by previous relationships with independent partners whose capabilities are still useful. Thus, incentives to integrate are low for more disintegrated assemblers. On the left side, one can see that these disintegrated assemblers have incentives to remain as buyers, whereas at the same time integrated ones have no reason to disintegrate, since their upstream capabilities have mostly been preserved by the innovation. Therefore, the overall result is that industry structure tends to be stable.

Some empirical results are in line with all these arguments. Walker and Weber (1987), for example, demonstrated that in the procurement of simple or low-uncertainty automotive components-thus similar to incremental innovations-capabilities were the most important factors driving make-or-buy decisions. Hoetker's (2005) analysis of the development of notebook displays also confirms that low technological uncertainty in new display technology, once again analogous to a context of incremental in-

\footnotetext{
${ }^{11}$ This assumption, resulting from our make-or-buy focus, should not be generalized. In the context of R\&D alliances, transaction costs stem mainly from hazards of proprietary information leakage (Sampson, 2004). And these hazards depend on the similarity between the capability endowments of the firms in the alliance: firms with very similar or dissimilar endowments have little to fear, whereas those in the intermediate range are the most at risk. In such a context, it is possible for transaction costs to move in the direction opposite coordination needs.
}

novation, led to procurement decisions made on the basis of technological capabilities.

We therefore propose the following.

Proposition 1: In the case of incremental innovation, the degree of vertical integration of an industry will not change.

The second case we are dealing with is that of modular innovation-that is, competencedestroying technological change for upstream suppliers without on upset of the architectural knowledge of systems integrators (Henderson \& Clark, 1990).

Because upstream capabilities are overturned (and assuming that the market will provide a pluralism of technological alternatives), integrated assemblers have strong incentives to access the market and, thus, disintegrate (see Figure 1). Arm's-length transactions will provide the required new capabilities and, at the same time, avoid the risks stemming from technological investments associated with internal development or an acquisition. It is not so much that the technology itself will quickly become obsolete in the near future but, rather, that the particular trajectories that will prove successful in this industry might not be completely known at the point when the innovation is first introduced.

Integration incentives, however, are also higher than in the case of incremental innovations. Although the technology may already be fomiliar to other industries, it may, in fact, be new to the focal industry. Therefore, assimilating it into products will include a certain degree of technological uncertainty, which will accordingly raise transaction costs. In addition, changes in the specific interface between the system core and the new module (or subsystem) will likely be required. ${ }^{12}$ As a consequence, closer coordination between assemblers and suppliers will be needed, especially if it is necessary to transfer tacit knowledge embedded in the new technology.

Furthermore, it is unlikely that long-term relationships will be able to play a role in decreasing these transaction and coordination costs. Because technological developments are thought to be path dependent, with a trajectory leading

\footnotetext{
${ }^{12}$ We are obviously eschewing pure modularity here, which, by definition, requires no interface change.
} 
to related technologies (Teece, 1996), one could expect modular innovations to emerge in the market from new entrants to the industry, making use of new or distant knowledge bases (Jacobides \& Winter, 2005). Assemblers would then have to work on new relationships. And since contractual learning is very relationship specific (Mayer \& Argyres, 2004), there are few spillovers from one partner to another. Switching suppliers thus means starting on a new learning path.

Because modular innovations bring together integration and disintegration incentives, it is not possible to theoretically predict the overall direction of vertical scope in an industry subjected to this kind of shock. In the real world, a number of factors external to our analysis, such as asset specificity (or lack thereof) or market uncertainty, might end up tipping the balance one way or another. The overall result at the industry level will also implicitly depend on the distribution of integrated versus disintegrated assemblers. However, concentrating on the issues discussed so for serves to enlighten us about possible dominating incentives. Lower transaction costs resulting, for example, from thick upstream markets, or lower coordination costs due to more codifiable knowledge or a relatively more stable interface, could lead to the domination of disintegration incentives. Moreover, the forther the new technology is from the assembler's knowledge base, the lower its absorptive capacity will be (Cohen \& Levinthal, 1990), making the assembler more likely to turn to the market. In contrast, integration would tend to prevail with thin upstream markets and high coordination costs emerging from a novel interface. The possibility of spillovers from this new technology to additional components or subsystems would also promote integration.

Existing empirical results show that industries where modular innovations occur exhibit a progressive disintegration of the value chain and a relatively high stability of players at the systems integrator level, with entry and exit occurring at the supplier level (Hobday, 1998). Examples include flight simulators (Miller, Hobday, Leroux-Demers, \& Olleros, 1995) and aircraft engines (Prencipe, 2000), where the main modular innovations were the substitution of digital or electronic components for older analog ones. Relating this to the contingencies discussed above, one can understand the empirical observations by recognizing that the new technology was probably highly codified, with a well-understood interface, leading to a plug-and-play situation. The new knowledge was also far from the assemblers' previous core competences.

Jacobides (2008) presents a complementary perspective on this last point. His analytical model shows that the correlation between firms' upstream and downstream capabilities might be a good predictor of vertical scope. The more positive the correlation, the more integrated the industry seems to become, and vice versa. In this sense, if the overturned upstream capabilities were previously positively correlated with the downstream (i.e., systems integration) capabilities in the industry, then a modular innovation that reduced this correlation would promote disintegration.

Thus, we argue that despite possible higher transaction costs and coordination needs arising from a modular innovation, the fact that upstream capabilities are overturned tends to dominate industry reorganization. To avoid the costs of internal development, or of an acquisition with the attached risks of technological obsolescence, previously disintegrated assemblers will likely remain so, at the same time that integrated ones will turn to arm's-length transactions.

Proposition 2: For modular innovations, the degree of vertical integration of an industry will decrease.

In the case of architectural innovation, where the core concepts and components are reinforced but their linkages change (Henderson \& Clark, 1990), ${ }^{13}$ upstream capabilities retain their importance. In the short run, upstream investments in modified subsystems have a low obsolescence risk. In other words, technological uncertainty resides in the new architecture that lies in the domain of the assembler's systems integration capabilities. ${ }^{14}$ Therefore, similar to the case of incremental innovations, the incen-

\footnotetext{
${ }^{13}$ Langlois (1998) and Davies (1997) use an analogous definition but call it "systemic innovation." But Davies also defines architectural innovation as "changes in functions of components and subsystems and how they are controlled to realise a common system goal" (1997: 234). This is a broader definition that we do not consider here.

${ }^{14}$ Uncertainty in architectural innovations is less about the newness of technologies and more about how the different components, modules, and subsystems best fit and work together in the new product architecture.
} 
tives to use arm's-length transactions are low for integrated assemblers.

An important difference between modular and architectural innovations is the larger number of interfaces linking subsystems that have to go through some change, even though the working concepts remain roughly the same. A new architecture can also introduce previously unknown interdependencies between components. These necessarily translate into significant knowledge transfers between suppliers and assemblers. The coordination required to achieve the necessary adaptation of the new architecture to customers' requirements would probably be better accomplished within the same organization. And the possibility of contract renegotiations due to technological uncertainty would concurrently increase transaction costs. If these integration incentives are high enough, as Figure 1 suggests, then long-term relationships might not be able to significantly decrease them.

Therefore, disintegrated assemblers can integrate ex post to save on transaction costs and to better coordinate the development and engineering of subsystems within the new architecture, without major concerns about missing technological alternatives. In addition to this response, integrated assemblers would for the same reasons tend to remain integrated after the technological shock. In agreement with these arguments, working with on internal supplier was extremely valuable for assemblers developing larger notebook displays, the equivalent of an architectural innovation, since changes were needed to many components because of physical (spatial) and power management issues (Hoetker, 2006: 507). ${ }^{15}$

Proposition 3: For architectural innovations, the degree of vertical integration of an industry will increase.

Finally, we have the case of industries facing a radical technological change, which is simul-

\footnotetext{
${ }^{15}$ Interestingly, Hoetker (2006) found similar results when the display innovation was related to its resolution and not its size, in which case it can be seen as closer to a modular innovation. But he also found that switching suppliers was easier in the case of the modular innovation. Given the ambiguity of Proposition 2, this result is not entirely surprising. Hoetker also suggests that in the context of notebook displays, the costs of establishing a modular system in the first place might prevent the outsourcing of higher-resolution displays.
}

taneously competence destroying for suppliers and systems integrators. It overturns not only the product architecture but also upstream capabilities. Therefore, similar to the case of a modular innovation, previously integrated firms have strong incentives to benefit from the pluralism of new technological solutions offered by the market, thereby avoiding the risks of obsolescence and the creation of organizational rigidities. This latter point might be particularly important because with radical innovations firms usually tend to compete in product design, not cost. And pushing the possibility frontier to address underserved customer needs might entail following a wrong technological route, backtracking, and then following a different path (Teece, 1996). Arm's-length transactions do facilitate this trial-and-error process.

Furthermore, radical innovations signal a break from the previous paradigm and, as such, tend to emerge with more interdependent rather than modular designs. Adaptation and experimentation to fulfill customers' requirements for the new technology will be the most important actions taken by firms. Avoiding transaction and communication costs arising from the constant changing of specifications and, consequently, multiple interactions with suppliers becomes paramount. These interactions are ill structured and complex (Macher, 2006), making it hard to transform tacit knowledge into abstract and general technological representations that facilitate the division of labor. This leads firms to rely on empirical methods (Arora \& Gambardella, 1994), something more easily accomplished inhouse. Integration then benefits assemblers to the extent that time to market of the new product is critical, and working with on internal supplier can speed up product development.

With both high integration and disintegration incentives, as illustrated in Figure 1, it is not possible, in principle, to theoretically posit how industry scope will evolve in response to a radical innovation. Many scholars have, however, suggested that innovations of a more systemic, interdependent, or state-of-the-art character call for backward integration into component manufacturing (Langlois, 1992; Macher \& Mowery, 2004; Teece, 1996). Jacobides and Winter (2005) also have argued that industries experience reintegration phases when superior capabilities emerge from knowledge bases that are different 
from those supporting the displaced technologies. $^{16}$

Afuah's (2001) study of the introduction of RISC microprocessors in the workstation market is in agreement with this view. RISC was not only an architectural innovation from the point of view of workstation manufacturers but also a radical, competence-destroying upstream innovation to chip producers. Afuah found evidence that manufacturers that integrated into RISC microprocessor production after the technological shock did significantly better than those that remained disintegrated. In line with this result, we propose that for radical innovations the benefits of inhouse organization will outweigh its costs.

Proposition 4: For radical innovations, the degree of vertical integration of an industry will increase.

It is important to note that although heterogeneity in capabilities does not enter our model explicitly, it does so implicitly in two ways. First, by considering that there are integrated and disintegrated assemblers in an industry prior to a shock, we account for the response of firms with and without upstream capabilities to formulate our propositions. Second, these propositions are at the industry level, so firm-level competences could lead a few individual firms to act in the direction opposite to that predicted on average. This would account for the high degree

\footnotetext{
${ }^{16}$ This last argument is also true of modular innovations. Yet we have posited a decrease in integration in this case.
}

of heterogeneity in vertical structure observed in many industries (Simon, 1991).

Revisiting, then, the question of when, in the presence of technological uncertainty, the competence perspective reinforces the TCE pledge for more integration and when it pushes in the other direction, the last three propositions above suggest in a nutshell that, for modular innovations, the benefits of accessing market capabilities might be greater than the costs of knowledge transfers, and this difference might be strong enough to offset the effects of higher transaction costs; in contrast, for architectural and radical innovations, the benefits of internal knowledge transfer and coordination seem to be greater than the value presented by foregone technological alternatives, thus reinforcing TCE effects. $^{17}$

Table 1 summarizes these results. Next to the characteristics of each innovation, it establishes whether there are increased ex post incentives either to disintegrate and access the market to avoid obsolescence or to internalize the transac-

\footnotetext{
${ }^{17}$ Decisions to integrate can also be viewed in light of real options theory: integration as a growth option and disintegration and market access as a deferral option. Experiential learning with similar technologies from a previous generation enhances the growth option of investing in the new technology. In contrast, higher risks of technological obsolescence increase the value of deferral options (Leiblein \& Ziedonis, 2007). In this context modular innovations would make deferral options more attractive to firms, whereas architectural innovations would increase the value of growth options. Thus, our predictions seem to be in agreement with insights from this fromework.
}

TABLE 1

Summary of Propositions ${ }^{\alpha}$

\begin{tabular}{|c|c|c|c|c|}
\hline Innovation & Characteristics & $\begin{array}{l}\text { Disintegration } \\
\text { Incentives } \\
\text { (Obsolescence Risk and } \\
\text { Market Alternatives) }\end{array}$ & $\begin{array}{l}\text { Integration } \\
\text { Incentives } \\
\text { (Transaction and } \\
\text { Coordination Costs) }\end{array}$ & $\begin{array}{l}\text { Predicted Direction of } \\
\text { Industry Integration }\end{array}$ \\
\hline Incremental & $\begin{array}{l}\text { - Autonomous } \\
\text { - Competence enhancing }\end{array}$ & Low & Low & No change \\
\hline Modular & $\begin{array}{l}\text { - Autonomous } \\
\text { - Competence destroying }\end{array}$ & High & High & ? (Decrease) \\
\hline Architectural & $\begin{array}{l}\text { - Systemic } \\
\text { - Competence enhancing }\end{array}$ & Low & High & Increase \\
\hline Radical & $\begin{array}{l}\text { - Systemic } \\
\text { - Competence destroying }\end{array}$ & High & High & ? (Increase) \\
\hline
\end{tabular}

${ }^{\alpha}$ The predicted effects of both TCE and competence arguments on vertical integration decisions lead to our four propositions. Results within parentheses indicate effects expected to dominate according to previous empirical studies. 
tion because of TCE and KBV arguments. When one type of incentive dominates, we indicate whether one should expect more or less industry integration. Question marks indicate when theory does not give a clear prediction, with effects within brackets corresponding to the direction of integration posited in our propositions, according to the limited empirical evidence available in the literature.

\section{Developing Endogenous Innovations}

So far, we have discussed what the industrywide response in terms of its vertical structure would be in the case of different kinds of exogenous technological shocks. In reality, because more innovative firms are usually in a better position to sustain a competitive advantage, managers are probably more interested in a normative theory of vertical structure with innovation as an ex ante goal, rather than a positive theory explaining how firms respond ex post to exogenous technological advances.

For systems integrators, the internal development of innovations is contingent on the degree of vertical integration of its value chain. For example, a firm needs an upstream segment to independently develop incremental and modular innovations. Moreover, the vertical scope chosen by a systems integrator shapes its cognitive scope and incentives regarding capability improvement and innovation (Jacobides \& Winter, 2005). Comparative advantages lead different types of firms to integrate or disintegrate, thus getting better at specific types of innovation. Therefore, the interest here lies in the management of the value chain structure, from the point of view of the assemblers, as a means of generating the different types of innovations in Henderson and Clark's (1990) typology.

Before proceeding, it is important to note that an efficient value chain structure does not necessarily have to be the same for firms responding to an exogenous innovation and for those trying to develop new products. Being an innovator or first mover entails facing higher risks and costs (e.g., higher R\&D expenditures), but also higher potential payoffs, than being a follower or second mover. ${ }^{18}$ Therefore, while incen-

\footnotetext{
${ }^{18}$ This is true even without strong appropriability, if innovators have access to complementary assets (Teece, 1986).
}

tives, competences, and transaction and bureaucratic cost considerations influence the structure of the value chain for firms trying to be innovators, it is possible that they do so differently from the previously discussed case of firms that are simply responding to innovations. High-powered incentives, for example, by definition tend to be much more important ex ante than ex post so that firms can overcome cognitive and bureaucratic barriers that support the status quo and hinder innovation (Teece, 1996).

We proceed in the same fashion as in the previous section. Starting once again with the case of incremental innovation, the question then is "Are firms better off trying to develop incremental product innovations inhouse or relying on upstream suppliers?" Naturally, this can only be answered with certainty if one knows a firm's capabilities-not in a static production sense but, rather, those capabilities associated with the continuous effort to innovate. An internal supplier that can provide a constant stream of incremental innovations is a potential source of competitive advantage, even in lowappropriability regimes. However, developing and maintaining capabilities superior to those available from independent suppliers might prove difficult in practice.

Independent suppliers have higher incentives to exploit new knowledge bases (Poppo \& Zenger, 1998) and to accumulate knowledge faster (Jacobides \& Winter, 2005), since the potential payoff for capturing market share in the form of orders from many assemblers is larger. In contrast, assemblers' fears of buying from competitors (de Figueiredo \& Teece, 1996) will prevent internal suppliers from reaching the scale to take full advantage of the stream of innovations. This translates into lower innovation incentives and higher inertia against change (Nooteboom, 1999). Furthermore, as discussed in the previous section, incremental innovations are characterized by both low transaction costs and coordination needs, reinforcing the advantages of disintegration. Since incremental innovations proceed through directional or local search, these arguments are also reinforced by Nickerson and Zenger's (2004) claim that markets are ideal to govern this type of search.

Hence, our initial conjecture of an innovative internal supplier might prove hard to encounter in practice. Although superior capabilities in in- 
cremental innovations might at some point in time reside with integrated assemblers, maintaining this technological edge inhouse over time might prove to be quite difficult and costly. Therefore, in a mature industry with an established dominant design and whose future technology trajectories seem to be dominated by incremental innovations, firms seeking to be innovative might be better off avoiding the bureaucratic costs of an inhouse supplier and relying on independent ones with higher incentives.

Nonetheless, by relying on independent suppliers, assemblers are not able to extract a competitive advantage from these upstream innovations per se, since they are available to all firms. Having given up their upstream capabilities, assemblers need to develop new ones in supply chain management. Not only do they need to concentrate on their core competences (Prahalad \& Hamel, 1990) in product architecture and systems integration, but they also need to learn how to take advantage of the pluralism of market alternatives-for example, by carefully managing a portfolio of suppliers that compete against each other, thus guaranteeing future innovative effort on their part (Fine \& Whitney, 1999).

The case of modular innovation is somewhat similar. But in addition to the incentive issues discussed above, the knowledge base behind it tends to reside farther from a firm's current capabilities. Because path dependency and cognitive biases usually limit the search for new technologies to areas related to present competences (Teece, 1996), integrated firms might find it very difficult to internally develop this kind of innovation. Therefore, unless an assembler has the right organizational culture and capabilities to search for distant technological solutions, it might be better off waiting for a modular innovation to emerge in the marketplace and then quickly moving to buy and incorporate it into its product, despite the higher coordination and transaction costs.

In practice, one way assemblers deal with these costs is to acquire knowledge associated with the innovation. Takeishi (2002) showed that automakers in Japan develop overlapping knowledge boundaries with their suppliers for the development of more innovative components and modules (closer in concept to modular innovations), even though their task boundaries clearly define them as buyers. They also develop a hybrid vertical structure (Dyer, 1996; Helper \& Sako, 1995), where they closely and simultaneously work with a selective small number of competing independent suppliers. This decreases transaction and coordination costs while at the same time providing the necessary incentives for suppliers to innovate by keeping them in check through the constant threat posed by competition. Shanley and Peteraf (2004) also have argued for the usefulness of this arrangement, dubbed a "vertical group," in more innovative settings.

The caveat is that for these hybrid governance structures to be successful, the assembler must ensure that suppliers in its vertical group are committed to being highly innovative, since modular innovations by definition entail the obsolescence of current capabilities. If these innovations always emerge from players outside the industry or simply outside the vertical group, the additional costs of maintaining this governance form might not pay off. In sum, assemblers trying to incorporate modular innovations into their products might find disintegration beneficial and decide to concentrate their capabilities in value chain management, but with an additional twist: knowledge management rises in importance, with firms extending their knowledge beyond their task boundaries (Brusoni, Prencipe, \& Pavitt, 2001; Fixson, Ro, \& Liker, 2005). In other words, assemblers seek to learn about novel and distant technologies that are not part of their current endowment, although they also need suppliers to extend their knowledge boundaries in the direction of architectural knowledge (Lee \& Veloso, in press; Takeishi, 2002).

Architectural innovations pose more interesting questions. A new architecture can not only provide a substantial advantage to an innovator in an established market (Henderson \& Clark, 1990) but can also open new submarkets. Assemblers then have high incentives to come up with architectural innovations. The main issue rests once again on whether more or less integrated assemblers are in a better position to innovate.

On the one hand, integration benefits the transfer of information and ideas with internal suppliers whose capabilities and skills will not be much affected by the technological change. It also saves on transaction costs due to uncertainty and prevents leakage of information 
about the new architecture. On the other hand, internal suppliers may create cognitive difficulties stemming from the information filters and communication channels embodied in the current architecture, thus delaying or preventing the innovation (Henderson \& Clark, 1990; Nooteboom, 1999).

Which forces prevail in practice is currently an open empirical question. Yet it is at least important to recognize that to limit the inertia associated with inhouse suppliers, an integrated firm would need an organizational culture that promoted outside-the-box thinking and innovation at every level. Rotating technical employees through different units or component areas might help to give them a stake in the bigger architectural picture and discourage the myopic protection of their own turf (Takeishi, 2002).

Nevertheless, even if an integrated firm accomplished this, it might still be at a disadvantage in the long run. If, as Teece (2000: Chapter 1) has argued, innovation at the architectural level occurs with much less frequency than the previous two types, disintegration before an architectural shift might be more beneficial overall, with firms taking advantage of the market for incremental and modular innovations in this period. Consequently, architectural innovation might be the one that most benefits from a hybrid supply chain. Avoiding full vertical integration should provide assemblers with market options for incremental and modular innovations, at the same time that it decreases cognitive biases, giving them a better chance to develop new architectures. And in this latter case, since upstream capabilities are not overturned, longterm relationships would be able to significantly decrease transaction and coordination costs.

Finally, for radical innovations, as we have discussed, system interdependencies favor integration, at least for later stages of product development. However, what is necessary at early stages and whether more or less integrated assemblers are in an advantageous position are less obvious. Integration might have an edge if internal suppliers are able to better promote the exchange of new ideas about emerging technologies (Hoetker, 2005)_or because interdependency and complexity need heuristic or cognitive search, something better accomplished by hierarchies (Nickerson \& Zenger, 2004).
The destruction of upstream capabilities, however, puts internal suppliers in a weak position to support this new product development. And they are bound to resist change (Teece, 1996), leading the assembler to miss technological opportunities in intermediate markets. Hybrid structures might be able to somewhat mitigate these hazards, but the infrequency with which radical innovations tend to come about leads one to be somewhat skeptical of this solution in the long run.

Based on the empirical results of his study of RISC workstations, Afuah suggested that firms "may be better off being vertically integrated into the major components that drive the discontinuity and better off not being vertically integrated into the components that drive the incremental change" (2001: 1225). The problem is that it is very difficult to know a priori which knowledge bases and capabilities will drive the radical or discontinuous change. A possible solution to this conundrum is for firms to establish strong $R \& D$ organizations, capable of supporting current operations and, perhaps more important, of constantly scanning the environment for novel technological opportunities (Argyres \& Silverman, 1999).

Recapitulating, this section addresses the notion that innovation and vertical structure might also be endogenously determined, as, for example, when more disintegrated firms get better at introducing incremental and modular innovations (Langlois \& Robertson, 1989) or when more integrated firms get better at introducing more systemic or interdependent advances (Sorenson, 2003). As always, there is no free lunch. Firms intending to become innovators need to develop specific capabilities suited for each kind of innovation.

Disintegrated assemblers, on the one hand, are required to improve the management of supplier relationships to extract maximum value from incremental or modular innovations introduced by independent suppliers. In the case of incremental innovation, it is simply a matter of putting requirements up for competitive bidding. For modular innovations, though, firms need to know more than they make (Brusoni et al., 2001). And in the case of new systemic trajectories, although disintegrated firms might have an initial cognitive advantage, they would also be at a later disadvantage coordinating the 
implementation of a new architecture with a myriad of independent suppliers.

Integrated assemblers, on the other hand, can take advantage of their organizational form to avoid transaction and coordination costs associated with architectural and radical innovations. In the case of autonomous innovations, however, they suffer from higher bureaucratic costs, cognitive biases, and inertia arising from their inhouse suppliers. They also miss the highpowered incentives flowing to independent suppliers. Therefore, they need additional competences not only to deal with these limitations but also to absorb external knowledge and quickly change technological trajectories if the initial innovative path proves to be the wrong one. The scholarship on vertical integration would greatly benefit from a more thorough investigation of this area.

\section{DISCUSSION}

An important contribution of this paper is its careful analysis of competence and transaction incentives in the context of the innovation typology offered by Henderson and Clark (1990). We propose a theory and framework to investigate the direction of industry integration after an exogenous shock of the four kinds described in the typology. The analysis complements Teece's (1996) treatment of autonomous and systemic innovations by dealing with the competencedestroying features of modular and radical ones. Although our propositions still agree that autonomous innovations will be related to disintegration and systemic innovations to integration, Table 1 indicates that this might not be the case in practice, and only future empirical studies will be able to verify this.

Another contribution of the paper is its clarification of the observed conflicting empirical evidence regarding the effect of technological uncertainty on the division of labor. Because uncertainty is contextual in nature, different technical developments that are the result of, say, similar incremental innovations may be seen by an engineer who is responding to a survey as being characterized by different levels of technological uncertainty. Analogously, engineers' perceptions about the magnitude of uncertainty across different innovation types might be deceptively similar. Both situations might lead to the contradictory results previ- ously described. If this is the case, tying technological uncertainty to the type of innovation will prove to be a better proxy.

The four propositions explain the little empirical evidence available and imply that keeping this bigger innovation picture in mind may help us to better analyze the effects of technological uncertainty on the evolution of an industry's vertical structure. Consider Walker and Weber's (1987) study of simple automotive components. As predicted by the discussion leading to Proposition 1, they found that existing capabilities are the decisive drivers of make-or-buy decisions. Moreover, when upstream markets are thick, higher technological uncertainty (indicating a transition from incremental to modular innovations) leads firms to buy. This contradicts TCE and KBV predictions that uncertainty leads to integration but is accounted for in Proposition 2 by the benefits of market alternatives. A failure to consider the intrinsic characteristics of the different types of innovations may then explain, for example, the overall lack of effect of technological uncertainty on licensing decisions described by Schilling and Steensma (2002).

Although knowing how to respond to exogenous technological shocks is important to managers, it is perhaps even more relevant for them to learn how to organize their firms' vertical structures so as to become innovators. Understanding what kinds of products, activities, and services to outsource prior to a determined innovative regime coming into place, along with understanding how to extract maximum value from suppliers in terms of product performance and innovative solutions, can lead to long-term competitive advantages and, consequently, survival.

Our analysis indicates that the disintegration called for in Proposition 2 may also be beneficial to firms, if future innovations remain in the incremental or modular categories. The case for integration called for by Propositions 3 and 4 as a response to exogenous architectural and radical innovations seems to be, at a minimum, weaker when dealing with ex ante efforts to be an innovator. Unfortunately, the only empirical work dealing with similar issues is Afuah's (2001), which does find ex ante disintegration benefits in the development of RISC workstations. No single governance mode seems capable of dealing with all four types of innovations 
all the time. Even the right scope may not always be a sufficient condition for success, since firms also need to develop and protect over time the right ancillary capabilities (e.g., value chain management, R\&D units).

In summary, this paper makes an explicit effort to link the evolution of product architecture through innovations to the vertical scope of an industry, with transaction costs and capabilities as moderators. Interestingly, despite technological change being at the core of life-cycle theories, the literature explicitly linking innovation to the division of labor and industry evolution is limited. We know that specialization is a major feature of industry life cycle (Stigler, 1951), but it is one that cannot be explained solely in terms of economies of scale resulting from market growth.

Cycles of disintegration and reintegration are observed in different industries (Macher \& Mowery, 2004). Reintegration seems to emerge when consumers become underserved by a certain technology (Cacciatori \& Jacobides, 2005; Christensen et al., 2002). But this is not a sufficient argument and needs to be tied to the innovations driving the evolution of technology. Although we agree with Macher and Mowery (2004) that there is a lack of generalizable findings in the literature, a better understanding of these cycles can be obtained by studying the types of innovations that emerge in an industry. For example, to the extent that incremental and modular innovations account for the bulk of innovations after the establishment of a dominant design (Utterback \& Abernathy, 1975), the combination of Propositions 1 and 2 with the endogenous discussion would signal a pattern of continuous disintegration, as observed in most industries (Stigler, 1951). Similarly, according to Propositions 3 and 4, architectural or radical innovations would lead to reintegration phases.

This study is not without its limitations. Although we have mostly talked about make-orbuy decisions as a dichotomous choice, vertical scope can vary between these two extremes in a more fine-grained manner (Jacobides \& Billinger, 2006). This is the reason, however, why our propositions speak broadly about the degree of vertical integration in an industry as increasing or decreasing. Future empirical work should be able to consider tapered integration.

This paper also sidesteps issues related to knowledge spillovers between upstream and downstream segments (Macher \& Mowery, 2004). Spillovers might be important because they can bridge knowledge gaps, alter the distribution of capabilities, and even allow upstream suppliers to integrate forward into assembly, a possibility not considered here. Similarly, we focus only on the response of assemblers and first-tier suppliers, and we ignore what happens to lower-tier suppliers. Interestingly enough, a modular innovation could lead an assembler to disintegrate and, at the same time, to increase the level of integration of first-tier suppliers.

Testing our propositions would require careful use of panel data. One would need data on one product system from an industry and to observe its evolution through time, determining the types of innovations that have shaped its technological trajectory. Simultaneously, it would be necessary to know whether parts and subsystems were manufactured or outsourced by assemblers.

Recent efforts to separate transaction costs from firm-level effects in make-or-buy decisions (Leiblein \& Miller, 2003; Poppo \& Zenger, 1998; Schilling \& Steensma, 2002) should be carefully expanded to a context of technological change, since the strength of these effects changes with different innovation types. For example, some constructs obtained from past surveys, such as component complexity and interdependency, are thought to influence firm boundaries through both knowledge-based and transaction cost mechanisms. With available data on component performance or quality, as in Takeishi's study (2002), it would be possible to follow Poppo and Zenger (1998), running separate regressions for inhouse and outsourced components, before and after a technological shock, to understand how these constructs affect market and organizational costs, thus affecting scope.

Data on competences (patents, for example, have been used in the past) would also come in handy to disentangle resources and capabilities from asset specificity effects. While the importance of the latter in static settings is well established, it would be useful to measure the influence of these effects under different kinds of innovation. Using constructs such as firm and industry standardization to proxy for specificity, a longitudinal data set might allow the use of simultaneous equation models to disentangle both effects (Schilling \& Steensma, 2002). 
With firm-specific capabilities emerging as the result of past governance choices, it would be interesting to identify leaders and followers in introducing different innovations. This would help distinguish their structures, shedding light on the endogenous innovation issues previously discussed. Great care should also be taken to separate KBV effects from human asset specificity. Learning and investments in specific skills will tend to improve knowledge transfer and coordination between suppliers and assemblers. However, language and communication barriers may persist owing to cognitive issues and organizational cultures, even after these investments are made.

Another interesting avenue of research would be to explore the differences between independent and vertical group suppliers-for example, in a keiretsu. In principle, transaction costs in general and fear of opportunistic behavior in particular should be much lower between assemblers and suppliers in vertical groups. However, it is not clear how much vertical and independent suppliers differ from assemblers in their respective organizational languages and codes. If vertical group suppliers enjoy no communication advantage, then the choice between intragroup or external procurement will be solely based on transaction cost considerations. Things will be different if group suppliers can develop organizational language and codes similar to their affiliated assembler's, or if longterm relationships and reputational effects can decrease transaction costs with independent suppliers. Surveys may be the best instruments to illuminate these issues.

Finally, any empirical model will need to control for additional factors or contingencies outside TCE and the competence perspective that influence boundary choices in innovative environments, such as entry barriers (Williamson, 1971), diversification (Kogut \& Zander, 1992; Leiblein \& Miller, 2003) and leading firms' strategies (Macher \& Mowery, 2004), institutional isomorphism (Lamoreaux, Raff, \& Temin, 2003), path dependency (Langlois, 1988; Simon, 1991; Teece, 1996), and network externalities (de Figueiredo \& Teece, 1996). This work should nevertheless pay off by broadening our understanding of not only how capability distributions influence vertical scope but also how innovations affect an industry's governance mode distribution as a consequence of second movers' re- sponses to new challenges and innovators' ex ante organizational efforts.

\section{REFERENCES}

Afuah, A. 2001. Dynamic boundaries of the firm: Are firms better off being vertically integrated in the face of a technological change? Academy of Management Journal, 44: 1211-1228.

Alchian, A., \& Demsetz, H. 1972. Production, information costs, and economic organization. American Economic Review, 62: 777-795.

Argyres, N. 1996. Evidence of the role of firm capabilities in vertical integration decisions. Strategic Management Journal, 17: 129-150.

Argyres, N., \& Silverman, B. 1999. R\&D, organization structure, and the development of corporate technological knowledge. Strategic Management Journal, 25: 929-958.

Armour, H., \& Teece, D. 1980. Vertical integration and technological innovation. Review of Economics and Statistics, 62: 470-474.

Arora, A., \& Gambardella, A. 1994. The changing technology of technological change: General and abstract knowledge and the division of innovative labour. Research Policy, 23: 523-532.

Balakrishnan, S., \& Wernerfelt, B. 1986. Technical change, competition and vertical integration. Strategic Management Journal, 7: 347-359.

Barney, J. 1986. Strategic factor markets: Expectations, luck, and business strategy. Management Science, 32: 12311241 .

Brusoni, S., Prencipe, A., \& Pavitt, K. 2001. Knowledge specialization, organizational coupling, and the boundaries of the firm: Why do firms know more than they make? Administrative Science Quarterly, 46: 597-621.

Cacciatori, E., \& Jacobides, M. 2005. The dynamic limits of specialization: Vertical integration reconsidered. Organization Studies, 26: 1851-1883.

Christensen, C., Verlinden, M., \& Westerman, G. 2002. Disruption, disintegration and the dissipation of differentiability. Industrial and Corporate Change, 11: 955-993.

Coase, R. 1937. The nature of the firm. Economica, 4: 386-405.

Cohen, W., \& Levinthal, D. 1990. Absorptive capacity: A new perspective on learning and innovation. Administrative Science Quarterly, 35: 128-152.

Conner, K., \& Prahalad, C. 1996. A resource-based theory of the firm: Knowledge versus opportunism. Organization Science, 7: 477-501.

Davies, A. 1997. The life cycle of a complex product system. International Journal of Innovation Management, 1: 229256.

de Figueiredo, J., \& Teece, D. 1996. Mitigating procurement hazards in the context of innovation. Industrial and Corporate Change, 5: 537-559.

Dyer, J. 1996. Does governance matter? Keiretsu alliances 
and asset specificity as sources of Japanese competitive advantage. Organization Science, 7: 649-666.

Fine, C., \& Whitney, D. 1999. Is the make-buy decision process a core competence? In M. Muffatto \& K. Pawar (Eds.), Logistics in the information age: 31-63. Padova, Italy: Servizi Grafici Editoriali.

Fixson, S., Ro, Y., \& Liker, J. 2005. Modularisation and outsourcing: Who drives whom? A study of generational sequences in the US automotive cockpit industry. International Journal of Automotive Technology and Management, 5: 166-183.

Foss, N. 1993. Theories of the firm: Contractual and competence perspectives. Journal of Evolutionary Economics, 3: 127-144.

Globerman, S. 1980. Markets, hierarchies, and innovation. Journal of Economic Issues, 14: 977-998.

Helper, S., MacDuffie, J., \& Sabel, C. 2000. Pragmatic collaborations: Advancing knowledge while controlling opportunism. Industrial and Corporate Change, 9: 443-488.

Helper, S., \& Sako, M. 1995. Supplier relations in Japan and the United States: Are they converging? Sloan Management Review, 36(3): 77-84.

Henderson, R., \& Clark, K. 1990. Architectural innovation: The reconfiguration of existing product technologies and the failure of established firms. Administrative Science Quarterly, 35: 9-30.

Hobday, M. 1998. Product complexity, innovation and industrial organisation. Research Policy, 26: 689-710.

Hoetker, G. 2005. How much you know versus how well I know you: Selecting a supplier for a technically innovative component. Strategic Management Journal, 26: 75-96.

Hoetker, G. 2006. Do modular products lead to modular organizations? Strategic Management Journal, 27: 501-518.

Jacobides, M. 2008. A model of how transaction costs, capabilities and limits to growth drive vertical scope. Organization Science, 19: 1-21.

Jacobides, M., \& Billinger, S. 2006. Designing the boundaries of the firm: From "make, buy or ally" to the dynamic benefits of vertical architecture. Organization Science, 17: $249-261$.

Jacobides, M., \& Hitt, L. 2005. Losing sight of the forest for the trees? Productive capabilities and gains from trade as drivers of vertical scope. Strategic Management Journal, 26: 1209-1227.

Jacobides, M., \& Winter, S. 2005. The co-evolution of capabilities and transaction costs: Explaining the institutional structure of production. Strategic Management Journal, 26: 302-326.

Kogut, B., \& Zander, U. 1992. Knowledge of the firm, combinative capabilities, and the replication of technology. Organization Science, 3: 383-397.

Lamoreaux, N., Raff, D., \& Temin, P. 2003. Beyond markets and hierarchies: Toward a new synthesis of American business history. American Historical Review, 108: 404-433.

Langlois, R. 1988. Economic change and the boundaries of the firm. Journal of Institutional and Theoretical Economics, 144: 635-657.

Langlois, R. 1992. Transaction-cost economics in real time. Industrial and Corporate Change, 1: 99-127.

Langlois, R., \& Robertson, P. 1989. Explaining vertical integration: Lessons from the American automobile industry. Journal of Economic History, 49: 361-375.

Lee, J., \& Veloso, F. In press. Interfirm innovation under uncertainty: Empirical evidence for strategic knowledge-partitioning. Journal of Product Innovation Management.

Leiblein, M., \& Miller, D. 2003. An empirical examination of transaction- and firm-level influences on the vertical boundaries of the firm. Strategic Management Journal, 24: 839-859.

Leiblein, M., \& Ziedonis, A. 2007. Deferral and growth options under sequential innovations. Advances in Strategic Management, 24: 225-245.

Leonard-Barton, D. 1992. Core capabilities and core rigidities: A paradox in managing new product development. Strategic Management Journal, 13: 111-125.

Macher, J. 2006. Technological development and the boundaries of the firm: A knowledge-based examination in semiconductor manufacturing. Management Science, 52: $826-843$.

Macher, J., \& Mowery, D. 2004. Vertical specialization and industry structure in high technology industries. In J. Baum \& A. McGahan (Eds.), Advances in Strategic Management, 21: 317-356.

Madhok, A. 2002. Reassessing the fundamentals and beyond: Ronald Coase, the transaction cost and resource-based theories of the firm and the institutional structure of production. Strategic Management Journal, 23: 553-550.

Masten, S. 1984. The organization of production: Evidence from the aerospace industry. Journal of Law \& Economics, 27: 403-417.

Masten, S., Meehan, J., \& Snyder, E. 1989. Vertical integration in the United States auto industry: A note on the influence of transaction specific assets. Journal of Economic Behavior \& Organization, 12: 265-273.

Mayer, K., \& Argyres, N. 2004. Learning to controct: Evidence from the personal computer industry. Organization Science, 15: $394-410$.

Mayer, K., \& Nickerson, J. 2005. Antecedents and performance implications of contracting for knowledge workers: Evidence from information technology services. Organization Science, 16: 225-242.

Miller, R., Hobdary, M., Leroux-Demers, T., \& Olleros, X. 1995. Innovation in complex systems industries: The case of flight simulation. Industrial and Corporate Change, 4: 363-400.

Monteverde, K. 1995. Technical dialog as an incentive for vertical integration in the semiconductor industry. Management Science, 41: 1624-1638.

Nelson, R., \& Winter, S. 1982. An evolutionary theory of economic change. Cambridge, MA \& London: Belknap Press of Harvard University Press. 
Nickerson, J., \& Zenger, T. 2004. A knowledge-based theory of the firm-The problem-solving approach. Organization Science, 15: 617-632.

Nooteboom, B. 1999. Innovation, learning and industrial organisation. Cambridge Journal of Economics, 23: 127-150.

Peteraf, M. 1993. The cornerstones of competitive advantage: A resource-based view. Strategic Management Journal, 14: 179-191.

Poppo, L., \& Zenger, T. 1998. Testing alternative theories of the firm: Transaction cost, knowledge-based, and measurement explanations for make-or-buy decisions in information services. Strategic Management Journal, 19: 853-877.

Prahalad, C., \& Hamel, G. 1990. The core competence of the corporation. Harvard Business Review, 68(3): 79-91.

Prencipe, A. 2000. Breadth and depth of technological capabilities in CoPS: The case of the aircraft engine control system. Research Policy, 29: 895-911.

Richardson, G. 1972. The organisation of industry. Economic Journal, 82: 883-896.

Riordan, M., \& Williamson, O. 1985. Asset specificity and economic organization. International Journal of Industrial Organization, 3: 365-378.

Sampson, R. 2004. Organization choice in R\&D alliances: Knowledge-based and transaction cost perspectives. Managerial and Decision Economics, 25: 421-436.

Schilling, M., \& Steensma, H. 2002. Disentangling the theories of the firm boundaries: A path model and empirical test. Organization Science, 13: 387-401.

Shanley, M., \& Peteraf, M. 2004. Vertical group formation: A social process perspective. Managerial and Decision Economics, 25: 473-488.

Silverman, B. 1999. Technological resources and the direction of corporate diversification: Toward an integration of the resource-based view and transaction cost economics. Management Science, 45: 1109-1124.

Simon, H. 1991. Organizations and markets. Journal of Economic Perspectives, 5(2): 25-44.

Smith, A. 1776. An inquiry into the nature and causes of the wealth of nations. Dublin: Whitestone.

Sorenson, O. 2003. Interdependence and adaptability: Organizational learning and the long-term effect of integration. Management Science, 49: 446-463.

Stigler, G. 1951. The division of labor is limited by the extent of the market. Journal of Political Economy, 59: 185-193.
Takeishi, A. 2002. Knowledge partitioning in the interfirm division of labor: The case of automotive product development. Organization Science, 13: 321-338.

Teece, D. 1980. Economies of scope and the scope of the enterprise. Journal of Economic Behavior \& Organization, 1: 223-247.

Teece, D. 1982. Towards an economic theory of the multiproduct firm. Journal of Economic Behavior \& Organization, 3: 39-63.

Teece, D. 1986. Profiting from technological innovation: Implications for integration, collaboration, licensing, and public policy. Research Policy, 15: 285-305.

Teece, D. 1996. Firm organization, industrial structure, and technological innovation. Journal of Economic Behavior \& Organization, 31: 193-224.

Teece, D. 2000. Managing intellectual capital: Organizational, strategic, and policy dimensions. New York: Oxford University Press.

Teece, D., Pisano, G., \& Shuen, A. 1997. Dynamic capabilities and strategic management. Strategic Management Journal, 18: 509-533.

Tushman, M., \& Anderson, P. 1986. Technological discontinuities and organizational environments. Administrative Science Quarterly, 31: 439-465.

Utterback, J., \& Abernathy, W. 1975. A dynamic model of process and product innovation. Omega, 3: 639-656.

Walker, G., \& Weber, D. 1987. Supplier competition, uncertainty, and make-or-buy decisions. Academy of Management Journal, 30: 589-596.

Wernerfelt, B. 1984. A resource-based view of the firm. Strategic Management Journal, 5: 171-180.

Williamson, O. 1971. The vertical integration of production: Market failure considerations. American Economic Review, 61: 112-123.

Williamson, O. 1975. Markets and hierarchies: Analysis and antitrust implications. New York: Free Press.

Williamson, O. 1983. The vertical integration of production: Market failure considerations. American Economic Review, 73: 519-540.

Williamson, O. 1985. The economic institutions of capitalism. New York: Free Press.

Williamson, O. 1999. Strategy research: Governance and competence perspectives. Strategic Management Journal, 20: 1087-1108.

Claudio Wolter (cwolter@cmu.edu) is a Ph.D. candidate in strategy, entrepreneurship, and technological change at Carnegie Mellon University. He received his M.Sc. in engineering and public policy from Carnegie Mellon. His research focuses on the effects of technological change on firms' boundaries and performance.

Francisco M. Veloso (fveloso@cmu.edu) is an associate professor of engineering and public policy at Carnegie Mellon University. He also has an appointment with the Universidade Católica Portuguesa. He received his Ph.D. in technology, management, and policy from MIT. He studies how firms and regions develop and leverage technological capabilities for growth. 
Copyright of Academy of Management Review is the property of Academy of Management and its content may not be copied or emailed to multiple sites or posted to a listserv without the copyright holder's express written permission. However, users may print, download, or email articles for individual use. 